Note

\title{
Specific Determination of Bromate in Bread by Ion Chromatography with ICP-MS
}

(Received May 9, 2002)

\author{
Takumi Akiyama*1, ${ }^{*}$, Michiko Yamanaka*2, Yukiko Date*2, Hiroki Kubota*1, \\ Megumi Hamano NagaokA*1, Yoko KaWASAKI*1, Takeshi Yamazaki*1, \\ Chikako Yomota*1 and Tamio Maitani*1 \\ $\left({ }^{* 1}\right.$ National Institute of Health Sciences: 1-18-1, Kamiyoga, Setagaya-ku, Tokyo 158-8501, Japan; \\ *2Yokogawa Analytical Systems Inc.: 2-11-13, Nakacho, Musashino-shi, \\ Tokyo $180-0006$, Japan; ${ }^{\dagger}$ Corresponding author)
}

\begin{abstract}
A sensitive method for detecting bromate in bread by ion chromatography with inductivelycoupled plasma mass spectrometry (IC/ICP-MS) was developed. Bromate was extracted from bread with water. The clean-up procedure included a $0.2 \mu \mathrm{m}$ filter, a $\mathrm{C}_{18}$ cartridge for defatting, a silver cartridge to remove halogen anions, a centrifugal ultrafiltration unit to remove proteins, and a cation-exchange cartridge to remove silver ions. A $500 \mu \mathrm{L}$ sample solution was applied to IC/ ICP-MS. The detection limit and the quantitation limit of bromate in the solution were $0.3 \mathrm{ng} / \mathrm{mL}$ and $1.0 \mathrm{ng} / \mathrm{mL}$, expressed as $\mathrm{HBrO}_{3}$, respectively, which corresponded to $2 \mathrm{ng} / \mathrm{g}$ and $5 \mathrm{ng} / \mathrm{g}$, respectively, in bread. Recovery of bromate was about $90 \%$, and the $\mathrm{CV}$ was about $2 \%$. Based on the detection limit in solution and recovery from bread, the detection limit of bromate in bread was estimated to be $2 \mathrm{ng} / \mathrm{g}$.
\end{abstract}

Key words: bromate; bread; ion chromatography with inductively-coupled plasma mass spectrometry; ICP-MS; silver cartridge

\section{Introduction}

Potassium bromate has long been used as a flour improver in the baking industry. Although it is permitted as a food additive in Japan ${ }^{1}$, its use is restricted to wheat flour used in baking because of its carcinogenicity ${ }^{2), 3)}$. Since the amount of bromate added, expressed as $\mathrm{HBrO}_{3}$, must not exceed $0.030 \mathrm{~g} / \mathrm{kg}$ of flour and bromate must be decomposed or removed before preparation of the finished food products ${ }^{1)}$, sensitive methods are needed to detect residual bromate in bread.

Several analytical methods for detection of bromate in bread, including $\mathrm{GC} / \mathrm{MS}^{4)}$ and HPLC with postcolumn reaction ${ }^{5-7)}$, have been reported, and one of them, the method using HPLC with postcolumn reaction, was published as a notification by the Ministry of Health and Welfare in 1997 ${ }^{8}$. Although this method had a very low detection limit for residual bromate and its sensitivity was improved recently ${ }^{7}$, it consumes a large amount of $o$-dianisidine, which is carcinogenic. It should also be noted that oxidants besides bromate are also detected by this method.

Inductively-coupled plasma mass spectrometry (ICP-MS) should be considered as an alternative method, because it can detect bromine specifically. There have been two reports on detection of bromate in bread by ion chromatography (IC) with ICP-MS. Dennis et al. ${ }^{9)}$ reported a detection limit of $20 \mathrm{ng} / \mathrm{g}$, while Heitkemper et $a l .{ }^{10)}$ reported a detection limit of $6 \mathrm{ng} / \mathrm{g}$ and the detection of $10 \mathrm{ng} / \mathrm{g}$ bromate in a spike experiment. This study reexamined the use of ICP-MS for detection of bromate in bread. The detection limit and recovery were examined by analyzing bread extracts by IC/ ICP-MS, and a detection limit lower than those previously reported was obtained.

\section{Materials and Methods}

\section{Samples and reagents}

Bread, bun and roll specimens were obtained from local stores. Bun specimens containing bromate was prepared by Yamazaki Baking Co., Ltd. from flour containing potassium bromate $\left(7.5 \mathrm{mg} / \mathrm{kg}\right.$ as $\left.\mathrm{HBrO}_{3}\right)$. Potassium bromate was purchased from Merck, and other chemicals were of reagent or HPLC grade. Ultrapure water (>18 M $\Omega \mathrm{cm}$ ) prepared with a Milli-Q SP Reagent Water System (Millipore) was used throughout the experiments.

Hereafter "bread" represents bread, buns or rolls.

\section{Extraction}

Each specimen was cut into small pieces and homogenized in a blender (Oster blender ST-1, Osaka Chemical). The crumbs $(10 \mathrm{~g})$ were placed in a $100 \mathrm{~mL}$ glass beaker and stirred with $50 \mathrm{~mL}$ of water for $15 \mathrm{~min}$, with a magnetic stirrer.

\section{Clean-up}

The filters and sample preparation cartridges used to 
clean up the bread extract were: filter paper (filter paper $5 \mathrm{~A}$, Advantec Toyo); a $0.2 \mu \mathrm{m}$ cellulose acetate syringe filter (Maishori disc W-25-2, Tosoh); a $\mathrm{C}_{18}$ sample preparation cartridge (Sep-Pak Plus tC18 Environmental Cartridge, Waters) activated in advance with $10 \mathrm{~mL}$ of methanol followed by $10 \mathrm{~mL}$ of water; a silver cartridge (OnGuard-Ag cartridge, Dionex) preconditioned with 50 $\mathrm{mL}$ of water; a centrifugal ultrafiltration unit (Ultrafree4 centrifugal filter unit UFV4 BTK, Millipore); and a cation exchange cartridge (TOYOPAK IC-SP M, Tosoh) preconditioned with $20 \mathrm{~mL}$ of water.

The bread extract was centrifuged at $8,000 \times g$ for 10 min, and the supernatant was filtered through filter paper. The filtrate was passed through a $0.2 \mu \mathrm{m}$ cellulose acetate syringe filter, an activated $\mathrm{C}_{18}$ cartridge and a silver cartridge, attached in tandem in that order. The first $2 \mathrm{~mL}$ of eluate was discarded, and the next $3 \mathrm{~mL}$ was placed in the upper cup of the centrifugal ultrafiltration unit and centrifuged till the filtrate in the reservoir exceeded $2 \mathrm{~mL}$. After passing $2 \mathrm{~mL}$ of filtrate through a cation-exchange cartridge, the first three drops were discarded, and the remaining filtrate was collected as a sample solution.

\section{IC/ICP-MS}

An Agilent 1100 system and an Agilent 7500 omega (Agilent Technologies Company) were used as the IC and ICP-MS systems, respectively, and they were connected by a $500 \times 0.3 \mathrm{~mm}$ i.d. ethylene tetrafluoroethylene (ETFE) tube. A GL-IC-A15 anion-exchange column connected to a GL-IC-A15G guard column (Hitachi Chemical) was used as the separation column. The operating conditions of IC and ICP-MS are described in Table 1. The bromate content was calculated from the peak area by an absolute calibration method.

\section{Results and Discussion}

\section{Sensitivity of the system}

Ammonium carbonate $(30 \mathrm{mmol} / \mathrm{L})$ were used as the mobile phase for IC. Ammonium salt was chosen to prevent salt deposition and clogging at the sampling orifice of the ICP-MS system by sodium in the mobile phase $^{11)}$. The injection volume was set at $500 \mu \mathrm{L}$ to achieve sufficient sensitivity. The retention time of bromate was $5.8 \mathrm{~min}$ at a flow rate of $1.0 \mathrm{~mL} / \mathrm{min}$. Bromide, which had a retention time of $8.0 \mathrm{~min}$, was separated from bromate.

The sensitivity of our IC/ICP-MS system was assessed. The detection limit and the quantitation limit for ${ }^{79} \mathrm{Br}$ and ${ }^{81} \mathrm{Br}$ were assessed from the baseline noise and the peak height of potassium bromate solution. Baseline noise, $N$, was defined as a signal response equal to twice the standard deviation of the baseline signal. The detection limit and the quantitation limit were calculated as the concentrations of bromate that would result in a peak height equal to three times and ten times, respectively, the baseline noise. When ultrapure water was analyzed, $N$ was 28 counts at $m / z 79$, and a detection limit $(S / N=3)$ of $0.3 \mathrm{ng} / \mathrm{mL}$ as $\mathrm{HBrO}_{3}$ and a quantita-
Table 1. Operating Conditions of IC and ICP-MS

\begin{tabular}{ll}
\hline IC conditions & \\
Column & GL-IC-A15G/GL-IC-A15 \\
Mobile phase & $30 \mathrm{mmol} / \mathrm{L}\left(\mathrm{NH}_{4}\right)_{2} \mathrm{CO}_{3}$ \\
Flow rate & $1.0 \mathrm{~mL} / \mathrm{min}$ \\
Column temperature & $40^{\circ} \mathrm{C}$ \\
Injection volume & $500 \mu \mathrm{L}$ \\
ICP-MS conditions & \\
Radio frequency power $1.5 \mathrm{~kW}$ \\
Plasma gas flow & $15 \mathrm{~L} / \mathrm{min}$ \\
Auxiliary gas flow & $1.0 \mathrm{~L} / \mathrm{min}$ \\
Carrier gas flow & $1.05 \mathrm{~L} / \mathrm{min}$ \\
Sampling depth & $8.0 \mathrm{~mm}$ from load coil \\
Nebulizer type & concentric nebulizer (quartz) \\
Interface & $\mathrm{Ni} \mathrm{sampling} \mathrm{cone,} \mathrm{Ni} \mathrm{skimmer} \mathrm{cone}$ \\
Detection mass & $\mathrm{Br}: \mathrm{m} / z=79,81$ \\
Dwell time & $0.5 \mathrm{~s} / \mathrm{amu}$ \\
\hline
\end{tabular}

tion limit $(S / N=10)$ of $1.0 \mathrm{ng} / \mathrm{mL}$ were calculated. They correspond to $2 \mathrm{ng} / \mathrm{g}$ and $5 \mathrm{ng} / \mathrm{g}$ bromate in bread, because a $10 \mathrm{~g}$ sample is extracted with $50 \mathrm{~mL}$ of water (see below). Similarly, a detection limit of $0.5 \mathrm{ng} /$ $\mathrm{mL}$ in solution and $3 \mathrm{ng} / \mathrm{g}$ in bread was calculated at $m / z 81$. Sensitivity was better at $m / z 79$ than at $m / z 81$. Aqueous solutions at concentrations of $0.5-5 \mathrm{ng} / \mathrm{mL}$ were analyzed, and a calibration curve was plotted according to the peak area of the chromatograms at $\mathrm{m} / \mathrm{z}$ 79. A good correlation $\left(R^{2}=1.000\right)$ was observed. The ionization efficiency of bromine was relatively low. High-resolution ICP-MS yielded better sensitivity in preliminary experiments, but it is elaborate and expensive. The sensitivity of our present system is adequate and practical.

\section{Clean-up}

The clean-up method, including a silver cartridge, that was developed in previous studies by Himata et al. 5),6) was applied to preparation of sample solutions, with some modifications. A $10 \mathrm{~g}$ bread sample was extracted with $50 \mathrm{~mL}$ of water, and after filtration through filter paper, a small portion of the extract was passed through a system constructed from a $0.2 \mu \mathrm{m}$ filter, a $\mathrm{C}_{18}$ cartridge for defatting, and a silver cartridge. The silver cartridge, which is a cation-exchange cartridge in silver form, was used to remove anions such as chloride and bromide that may affect the baseline noise of bromine and the resolution of the bromate peak. The centrifugal ultrafiltration unit was then used to remove proteins, and the filtrate in the lower tube was applied to a cation-exchange cartridge to remove silver ions. The volume of the final sample solution was about $1.5 \mathrm{~mL}$. Assuming no loss, $5 \mathrm{ng} / \mathrm{g}$ of bromate in a bread sample corresponds to $1 \mathrm{ng} / \mathrm{mL}$ in the final solution.

\section{Analysis of bread samples}

Sliced bread A, which had been demonstrated in advance to be made without potassium bromate, was used to evaluate the detection limit, the quantitation limit, and recovery. First, a blank bread sample was analyzed 

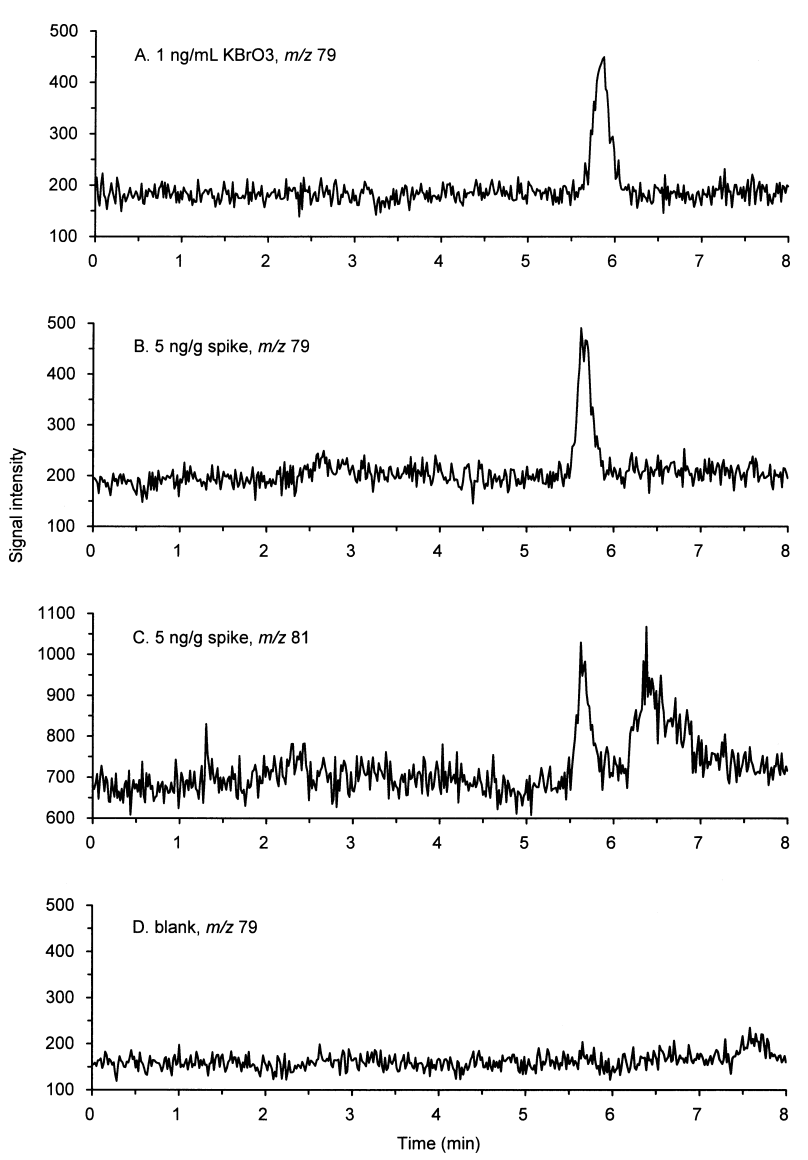

Fig. 1. Chromatograms of spiked and blank samples of sliced bread A

A: aqueous solution of potassium bromate; B and C: spiked sample; D: blank sample

A, B and D: chromatograms at $m / z$ 79; C: chromatogram at $m / z 81$.

after extraction and the clean-up procedure. No peak was observed in the chromatogram at $m / z 79$ (Fig. 1D), and the baseline noise $(N)$ of the blank was 30 counts at $m / z 79$. Based on the $N$ value, a detection limit $(S / N=$ 3) of $0.3 \mathrm{ng} / \mathrm{mL}$ as $\mathrm{HBrO}_{3}$ and a quantitation limit $(\mathrm{S} / N$ $=10$ ) of $1.0 \mathrm{ng} / \mathrm{mL}$ were calculated. These values correspond to $2 \mathrm{ng} / \mathrm{g}$ and $5 \mathrm{ng} / \mathrm{g}$ bromate in bread. They are almost the same as those obtained from ultrapure water. Components from the bread matrices did not affect the baseline noise. Since several peaks were observed up to $20 \mathrm{~min}$ when the same sample was analyzed by IC with UV detection or conductivity detection, the interval between the two injections was set at 20 min to allow these components to elute from the column.

A spiked bread sample to which potassium bromate was added at a concentration of $5 \mathrm{ng} / \mathrm{g}$ (expressed as $\mathrm{HBrO}_{3}$ ) was prepared, and the extract was analyzed after the clean-up procedure. A clear bromate peak was detected in the chromatogram at $m / z 79$ (Fig. 1B) as well as at $m / z 81$ (Fig. $1 \mathrm{C}$ ). The retention time of the bromate peak was $5.6 \mathrm{~min}, 0.2 \mathrm{~min}$ shorter than that of the aqueous potassium bromate solution. This difference may be attributable to anionic substances in the sample.

Recovery and reproducibility were also examined. The reproducibility of the instrument was assessed first. Several preparations were mixed in a tube, and this homogeneous sample was injected 5 times. Average recovery was $88 \%$, and $\mathrm{CV}$ was $2.1 \%$. Next, the reproducibility of the entire analysis was examined by analyzing 3 independent preparations. Average recovery was $90 \%$, and CV was $1.9 \%$. The clean-up procedure did not affect reproducibility, because no significant difference was observed between the CV of 3 preparations and of 5 injections of the same preparation. The blank sample solution was analyzed after adding potassium bromate to a final concentration of $1 \mathrm{ng} / \mathrm{mL}$ as $\mathrm{HBrO}_{3}$. Recovery was $100 \%$, and the loss of $10 \%$ can therefore be attributed to the clean-up procedure alone. Based on the detection limit in solution and recovery of the clean-up procedure, a detection limit as $\mathrm{HBrO}_{3}$ of 0.4 $\mathrm{ng} / \mathrm{mL}$ in the sample solution and $2 \mathrm{ng} / \mathrm{g}$ in bread was estimated. A quantitation limit of $1.2 \mathrm{ng} / \mathrm{mL}$ in the sample solution and $6 \mathrm{ng} / \mathrm{g}$ in bread was estimated in a similar manner.

Bun specimens containing bromate, made from flour containing potassium bromate $\left(7.5 \mathrm{mg} / \mathrm{kg}\right.$ as $\left.\mathrm{HBrO}_{3}\right)$, were analyzed. Bromate was detected at $6.2 \mathrm{ng} / \mathrm{mL}$ in the sample solution, which corresponded to $31 \mathrm{ng} / \mathrm{g}$ bromate in the bun. No bromide was detected. Three commercial baked goods, sliced bread B, a roll, and a bun, were also analyzed, and no bromate was detected.

In summary, a detection method for bromate in bread by IC/ICP-MS was developed. IC on an anion-exchange column and ammonium carbonate successfully separated bromate and bromide ions. A clean-up method that used a silver cartridge to remove halogen anions was applied. A detection limit of $2 \mathrm{ng} / \mathrm{g}$ and a quantitation limit of $5 \mathrm{ng} / \mathrm{g}$ as $\mathrm{HBrO}_{3}$ in bread were calculated. Recovery of bromate was about $90 \%$, as estimated on the basis of spike experiments. From the detection limit in solution and recovery from bread, the detection limit was estimated to be $2 \mathrm{ng} / \mathrm{g}$ bromate in bread.

\section{Acknowledgements}

The authors wish to thank Yamazaki Baking Co., Ltd. for the preparation of bun specimens.

\section{References}

1) Japan's Specifications and Standards for Food Additives, 7th Ed., Ministry of Health and Welfare, Japan (1999).

2) Kurokawa, Y., Hayashi, Y., Maekawa, A., Takahashi, M., Kokubo, T., Odashima, S., Carcinogenicity of potassium bromate administered orally to F344 rats. J. Natl. Cancer Inst., 71, 965-972 (1983).

3) Kurokawa, Y., Maekawa, A., Takahashi, T., Hayashi, Y., Toxicity and carcinogenicity of potassium bromate-A new renal carcinogen. Environ. Health Perspect., 87, 309335 (1990).

4) Himata, K., Kuwahara, T., Ando, S., Maruoka, H., Determination of bromate in bread by capillary gas chromatography with a mass detector (GC/MS). Food Addit. 
Contam., 11, 559-569 (1994).

5) Himata, K., Noda, M., Ando, T., Yamada, Y., Measurement of bromate in bread by high performance liquid chromatography with post-column flow reactor detection. Food Addit. Contam., 14, 809-818 (1997).

6) Himata, K., Noda, M., Ando, T., Yamada, Y., Measurement of bromate in bread by liquid chromatography with post-column flow reactor detection. J. AOAC Int., 83, 347-355 (2000).

7) Kawasaki, Y., Kubota, H., Yomota, C., Maitani, T., Improved sensitive determination method for bromate in bread. Shokuhin Eiseigaku Zasshi (J. Food Hyg. Soc. Japan), 43, 221-224 (2002).

8) Notification No. 119 (Sep. 12, 1997), Director-General of Environmental and Health Bureau, Ministry of Health and Welfare, Japan.
9) Dennis, M. J., Burrel, A., Mathieson, K., Willetts, P., Massey, R. C., The determination of the flour improver potassium bromate in bread by gas chromatographic and ICP-MS methods. Food Addit. Contam., 11, 633-639 (1994).

10) Heitkemper, D. T., Kaine, L. A., Jackson, D. S., Wolnik, K. A., Practical applications of element-specific detection by inductively coupled plasma atomic emission spectroscopy and inductively coupled plasma mass spectrometry to ion chromatography of foods. J. Chromatogr. A, 671, 101-108 (1994).

11) Yamanaka, M., Sakai, T., Kumagai, H., Inoue, Y., Specific determination of bromate and iodate in ozonized water by ion chromatography with postcolumn derivatization and inductively-coupled plasma mass spectrometry. J. Chromatogr. A, 789, 259-265 (1997). 